\title{
The Customs of Conflict Management among Corporate Executives
}

This article examines the customs of conflict management among executives at the tops of two large business organizations. The argument advanced here derives from the notion that conflict management varies with the informal norms that govern interpersonal networks. Ethnographic, social network, and perceptual data collected in the present investigation suggest that where executives experience fragmented and atomized interpersonal networks, they are more likely to manage conflict without confrontation than in networks of strongly and densely connected individuals. The results of this study carry implications for the relationship between attitudes and behaviors among corporate managers regarding confict management, for the normative bases of decision making, and for the "ffi" between social context and routine conflict management.

\section{$\mathrm{L}$} AURA NADER WROTE IN 1969 THAT SOCIAL SGIENTISTS focused much of their scholarly attention on the less privileged, largely excluding those in socially powerful positions. The consequences of such a focus, she argued, included a relative lack of knowledge of higher social strata and a lack of vertical generalization of most social scientific theories. She argued that social scientists needed to "study up," especially in large bureaucracies, in order to be scientifically and socially adequate in understanding human behavior.

Nowhere has this bias been more apparent than in the study of disputing and conflict management-an area that has traditionally been central in the anthropology of law. During the last 25 years, anthropologists and sociologists studying disputing have developed theories that emphasize the importance of social context for explaining how conflict is handled. Scholars first used this approach to study conflict management in non-Western societies and then imported them to explain disputing among Western working- and middle-class people. Much less is known about the efficacy of such approaches for studying bureaucratic elites.

This article examines the customs of conflict management among executives at the tops of two large business organizations. The argument advanced here derives from the notion that conflict management varies with the informal norms that govern interpersonal networks (e.g., Horwitz 1990:5; see Black 1984, 1990). The central hypothesis investigated is that where executives experience fragmented and atomized interpersonal networks, they will be more likely to manage conflict without confrontation than in networks of strongly and densely connected individuals. The results of this study carry implications for the relationship between attitudes and behaviors among corporate managers regarding conflict management, for the normative bases of decision making, and for the "fit" between social context and routine conflict management.

\section{Two Approaches to Conflict Management}

Disputes begin when someone has a real or imagined grievance against someone or something else (Nader and Todd 1978; Merry 1979; Black 1984, 1990; Morrill 1989).

CALVIN MorRILL is Assistant Professor, Departments of Communication and Sociology, University of Arizona, Tucson, AZ 85721. 
This is called the "preconflict" or "grievance" stage (Nader and Todd 1978:14; cf. Morrill 1989:391), which may develop into open conflict. Some scholars define conflict as confrontation among the principals to a grievance-when an aggrieved party "throws the gauntlet down" and directly proceeds against an adversary, as Nader and Todd (1978:15) evocatively argue. For present purposes, conflict is considered more broadly to refer to the communication of grievances confrontationally or nonconfrontationally between principals (Morrill 1989:391; cf. Starr 1978:123). Confrontation refers here to the airing of grievances via talk or physical action directly between the principals. Nonconfrontation occurs when grievances are expressed without direct verbal communication or physical action. Such a broadening of the definition of conflict management allows for a wider range of grievance-based phenomena to be analyzed and does not conflate confrontation with conflict. Mutual avoidance would be an example of nonconfrontational conflict, while negotiating a conflict would be an example of confrontational conflict handling. Disputes occur when conflicts escalate to a public arena and third parties are drawn in either as supporters or settlement agents (Morrill 1989:392). Studies of disputing frequently focus on how and under what conditions principals pursue grievances. The role of confrontational means, such as verbal or physical attacks (with supporters), negotiation via third parties, or institutionalized forums, and nonconfrontational means, such as collective avoidance or simply doing nothing, are typically considered (Black 1990; Merry 1990:90).

One answer to the question of how grievances are pursued derives from several strains of "choice theory" that March (1988) argues underlie much of the descriptive and prescriptive wisdom about decision making in organizations. As outlined by March (1988:2), decision making from the choice perspective is "intentional, consequential, and optimizing." Thus, managers are "cast in the role of rational men" who must optimize profit for their organizations (Collins and Moore 1970:7). Such an orientation can be found in the classical managerial theorizing of Henry Fayol (Mintzberg 1973:9), who argued in the late 19th and early 20th centuries that managers are composites of rational functions: planning, organizing, coordinating, commanding, and controlling. Choice theory also undergirds portrayals in popular business magazines such as Forbes and Fortune of managers as Napoleonic "men on white horses" making important decisions for the good of their firms based on an objective and definable "big picture."

Implicit in many theories of conflict management in organizations is the assumption that managers make rational choices about how to handle interpersonal conflict based on the seriousness of conflict issues. Walton (1969), for example, argues that managers lower the personal and organizational costs of interpersonal conflict by confronting colleagues in nonthreatening ways. This is especially true where conflicts are "deeply felt" and "long-standing" among the principals. In a similar vein, Bergmann and Volkema (1989) suggest that conflict-issue seriousness relates to the number of organizational members affected. The more organizational members affected, the greater the potential damage to the organization, and the greater the need for managers to engage in some form of direct communication regarding their problems. In general, then, serious conflict issues are regarded from a choice perspective as those that "seriously and rapidly impede the progress of the organization" (Frost 1987:510). These arguments suggest two hypotheses about conflict management: (1) executive grievances perceived by disputants as serious and in need of immediate attention will be managed confrontationally; and (2) grievances defined as less serious by aggrieved parties will be managed nonconfrontationally.

A second perspective on conflict management has its wider origins in anthropological and sociological studies of disputing that emphasize the importance of concrete social relationships and their attendant norms (Colson 1953; Gluckman 1973; Macaulay 1963; Baumgartner 1984, 1988; Bohannan 1967; Koch 1974; Nader and Todd 1978; Black 1990). The second perspective is also implied in emerging theories of managerial behavior that emphasize the normative bases of managerial decisions within the context of their proximate social relations (Fligstein 1990; Dimaggio and Powell 1991). This contextual 
approach denies instrumentality related to organizational efficiency as an exclusive factor in the structuring of grievance pursuit and focuses instead on people's actions as products of their immediate social contexts. On the one hand, people's interests are constrained and enabled by their positions in patterns of informal and formal relations (e.g., interpersonal networks and authority ties). At the same time, different "local cultures" (Geertz 1973) associated with particular patterns of social networks also enable and constrain social action (Van Maanen and Barley 1985). Social structure and symbol systems ("culture") are thus enmeshed in one another, each acting on the other.

Baumgartner's $(1984,1988)$ studies of working- and middle-class conflict provide a concise application of the social context approach to conflict management. Baumgartner argues that "loose-knit" and "dense-knit" networks are systematically associated with particular customs of grievance pursuit. Loose-knit (or weak-tie) networks, in this sense, refer to settings in which people have sparse communication about task- and relationally oriented issues and little interdependence (of information or material resources) with each other. Social ties within such networks also tend to be "single stranded" in that they encompass only one or a few activities. Dense-knit networks, in contrast, exhibit high degrees of communication and interdependence between actors. Social ties in such settings tend to be "multiplex," in that they involve different activities and types of relations (Barnes 1969). Baumgartner specifically predicts that individuals living in loose-knit settings will likely opt for subtle, nonconfrontational forms of pursuit, whereas aggrieved parties will be more likely to opt for confrontation in dense-knit networks. These assertions rest on factors that individuals experience simultaneously in loose-knit and denseknit settings.

In loose-knit settings, disputants enjoy the social distance and autonomy necessary to easily withdraw from conflict rather than confront opponents. Second, the paucity of social ties decreases opportunities to mobilize "power groups" who would aid disputants directly in their grievances, thus syndicating the risks of confrontation (Gulliver 1979). Finally, actors in socially fragmented settings have sparse knowledge of each other's general activities and conflicts. In one sense, disputants in loosely tied networks are treated as "first offenders," who are handled less severely when in conflict. The opposite prevails in dense-knit networks where multiple communication channels spread information rapidly, especially gossip about conflict.

Loose- and dense-knit settings also have affinities with local norms of conflict management that define "what is worth fighting for, and what kinds of remedies are acceptable" (Merry and Silbey 1984:157). Loose-knit settings are likely to be associated with what Baumgartner terms "moral minimalism," which frames the proper handling of grievances as exercises in restraint, inaction, and subtlety. In such a setting, nothing is "worth fighting for," at least not confrontationally. What people "fight" for within a culture of moral minimalism is independence and they do so via covert tactics, such as avoidance or toleration. Acceptable remedies under such conditions typically consist of being left alone to pursue independent activities. In contrast, dense-knit settings exhibit cultures of confrontation in which the public recognition of conflict and its outcomes are central. In such cultures, acceptable remedies may take on win-lose dimensions, but may also approach compromise.

The context approach suggests two more hypotheses: (3) corporate executives embedded in loose-knit intra-organizational networks should experience moral minimalist cultures and handle much of their conflicts via nonconfrontation, and (4) executive opponents in dense-knit networks should experience confrontational cultures and routinely confront each other with grievances.

\section{Research Sites}

The hypotheses above were investigated at two corporations, which will be given the pseudonyms Independent Accounting and Playco. The executive settings in these com- 
panies offered the opportunity for a partially controlled comparison. Both companies are located in the same geographical locale, were both financially solvent when studied, and have similar demographics (executives tended to be White, male, 35-60 years of age, and have graduate degrees; cf. Kanter 1977:29-68). At the same time, they differ in that one is an international headquarters (Playco) while one is a regional headquarters (Independent Accounting). However, Independent's regional office operates autonomously from the national headquarters. The companies also differ in their products, as discussed below. ${ }^{1}$

\section{Independent Accounting}

Independent Accounting is an international audit firm with over 20,000 employees, working in several dozen branch offices, who generated just over one billion dollars in sales during 1986. In addition to tax and audit services, the firm offers an array of management consulting services. The company is owned and managed by a few hundred partners scattered in its branch offices. Its largest branch office is located on the West Coast, has twenty-one partners, several hundred nonpartner professionals, and other support staff.

Work at Independent revolves around what are called "engagements" between clients and partners (and their staffs). The audit of an engineering firm's assets prior to its sale to an oil company, the preparation of taxes for a commercial bank, or the design of an information management system for a manufacturer all illustrate engagements. Partners head most engagements and require large staffs because of the size of the firm's commercial clientele.

The partnership has a formal hierarchy, but, like many professional firms, partners at Independent enjoy a great deal of autonomy (see generally, Abbot 1988; Maister 1984). There are not regular reporting schedules and few formal meetings among partners. As one regional partner observed:

Each partner runs his engagements like his own little firm. He is responsible for developing new clients, making his engagements profitable, and doing good work. It's not like a manufacturer where the senior vice president walks into a plant and everybody dances to his tune.

In addition, all partners transfer more than once between offices during their careers. Most partners also have second offices and spend one to two days per week out of their offices with clients. Fewer than $5 \%$ of the partners at Independent Accounting left the firm in the ten years prior to this study.

\section{Playco}

Playco manufactures electronic learning aids, computers, and toys for children, and owns several other entertainment subsidiaries. It has 35,000 employees, 43 executives at its headquarters, grossed over one billion dollars in sales during 1986, and is publicly owned. Playco's executives and Independent Accounting partners share similar demographic characteristics. Unlike Independent Accounting, however, Playco's executives are organized into a "matrix" structure (Davis and Lawrence 1977) in which its departments (operations, R\&D, marketing, sales, finance, planning, engineering, and administration) are crosscut by product teams responsible for the company's product lines. Playco executives thus have a "two-boss" or "multiple command" system (Davis and Lawrence 1977:5). As such, most Playco executives (below the rank of president) report to a departmental head and product team leader (who are always top marketing managers). Similar ambiguities in authority exist at the top of the executive ranks. In the "office of the presidents," the chief executive officer has nominal authority over two other presidents, each of whom is responsible for the firm's international and domestic divisions, respectively.

\section{Method}

I gained access to both study sites through personal ties to a consultant who worked with the firms. I then adopted the role of a "naive observer" who needed education in 
the "ways of the business world." This strategy proved successful for maintaining access. A total of 217 hours were spent in contact with Playco personnel and 236 hours with Independent Accounting personnel over a 14-month period during 1984 and 1985. Since then, contact has been maintained with some informants who work with the firms.

\section{Network Data}

The factors in the social context approach to conflict management hinge upon the contrast between two network properties: the presence or absence (e.g., fragmentation) and the dimensions (e.g., multiplexity) of ties between people. The goal of the network data collection aspect of the fieldwork, therefore, was to measure interpersonal executive networks along the dimensions specified by Baumgartner (1984): regular communication, interdependence, the sharing of normative information ("gossip"), and partisanship. These dimensions also cover two broad dimensions that have been argued to constitute the basis for all ties: verbal exchanges of affect or information (Minor 1983:227). Executives responded to a series of sociometric questions at the end of open-ended interviews (designed to yield ethnographic and conflict data; see below). The questions were:

1. Among your executive colleagues, who do you regularly talk with about work-related issues only? (This question was further clarified to focus on technical issues and to mean two to three times per week, including meetings.)

2. Among your executive colleagues, are there any you regularly need to receive information from in order to make timely and effective decisions? (This question was again clarified to mean two to three times per week.)

3. Would you name the executives who you have called on in the last six months to be your ally during interpersonal problems or conflicts with other executives?

4. Do you ever talk about interpersonal or other work-related problems either you or other colleagues are experiencing? If yes, with whom? (This question was also clarified by asking: In whom do you confide on a weekly basis?)

Network boundaries were defined according to whether informants or those people they named were executives, that is, whether they held at least the title of vice president or partner (e.g., Kotter 1982:2). This approach follows positional criteria by which incumbents are included in networks by the "presence or absence of some attribute, most commonly occupance of a position in a formally constituted group" (Laumann, Marsden, and Prensky 1982:23).

People-by-people matrices were then formed based on executive choices in response to each of the four questions. Complete network data were collected for 19 out of 21 partners at Independent Accounting, and for 39 out of 43 executives at Playco. Thus, 19-by-19 matrices were constructed for Independent and 39-by-39 matrices for Playco. "Directionality," then, or who chooses whom (Mitchell 1969:20-29) is less important than the mere existence of social ties.

The data were analyzed by first comparing density measures for uniplex and multiplex executive networks across the firms and then across work units within the firms. Density refers to "the extent to which links which could possibly exist among persons do in fact exist," and is determined via: $N a / N(N-1)$ where $N a$ refers to the actual number of ties and $N$ to the total number of persons in the network including ego (Mitchell 1969:18). Multiplex network densities were calculated by taking the mean densities of unions of ties with two and three dimensions. For example, one possible multiplex tie between actors with two dimensions would be executives who talked with each other about work-related issues and gossiped (shared normative information). Another two-dimensional multiplex tie possible in the present investigation would be when executives communicated about work-related issues and were allies of each other. A three-dimensional multiplex tie would be possible if executives talked about work-related communication, were allies, and gossiped with each other. Because different combinations of multiplex ties were possible, the mean density across the combinations of multiplex ties was used in comparing multiplex 
ties of two and three dimensions. The raw density was used to compare multiplex ties composed of four dimensions because only one such network was possible with these data.

\section{Ethnographic and Conflict Data}

Ethnographic data were collected on executive practices and beliefs about conflict management using a variety of field techniques: structured and unstructured interviewing, observations, and document collection. Ethnographers have fruitfully used these methods to study conflict management in other cultures (e.g., Koch 1974; Nader and Todd 1978), in American communities (Merry 1979; Buckle and Thomas-Buckle 1983; Baumgartner 1984, 1988), and most recently in formal organizations (Kolb and Bartunek 1992).

These strategies were also used for a "trouble case method" (following Llewellyn and Hoebel 1983) to understand how executives pursue their grievances. This method entails investigating "instances of hitch, dispute, grievance, trouble; and inquiry into what the trouble was and what was done about it" (Llewellyn and Hoebel 1983:21). Beyond this general notion, there is little agreement about the method and what constitutes a trouble case (Cain and Kulcsar 1981-82; Menkel-Meadow 1983; Greenhouse 1986).

The present investigation focused on interpersonal grievance expressions embedded in larger trouble cases ("extended trouble cases," to borrow from Van Velsen 1967) bounded by the issues involved. A trouble case in the present investigation might begin when an executive avoids a "bothersome" colleague by not attending meetings at which the latter will be or when a colleague complains to another that the latter hasn't been a tough enough ally in executive meetings. Cases may last for a few hours or stretch into weeks or months with different behaviors used to pursue the same issues until an outcome of some kind occurs. Sometimes, extended cases become involved with other cases as the issues and allies change in midstream.

At Independent Accounting, 77 executive grievance expressions were collected (contained in 54 cases) and 103 grievance expressions were collected at Playco (contained in 39 cases). Of the 93 cases collected from the settings, 66 were collected in interviews. Each interview began with a brief description of the purpose of the project: to study "people problems" among top managers. Each informant was then asked questions about his or her experiences at work, including experiences with colleagues who the informant found objectionable in some way. Principals in conflicts also responded to questions about the seriousness of the issues involved in terms of their effects on the corporation and the urgency of the situation. Qualitative responses were then coded into dichotomous variables for quantitative analysis.

\section{Problems in the Field}

Several researchers question the accuracy of informant recall data (Killworth and Bernard 1976; see the review in Freeman, Romney, and Freeman 1987). For network data, the problems center on recall of interaction patterns. Perceptual and conflict data could also suffer from recall biases in terms of informants' perceptions at the time of conflict versus at the time of an interview. Recently, Freeman, Romney, and Freeman (1987) argued that collecting accurate data is less a question of which type of data is best for all research purposes-observational or informant recall data-than a question of the purposes for which the data will be used. Informants tend to be an inaccurate data source for synchronic social interaction, but do seem to accurately capture behavioral norms in a particular setting over time; in effect, people's recall is biased toward what usually happens in a setting. The network data for the present investigation were intended to represent behavior over time, thus suggesting the efficacy of the data collection methods. Data on conflict management are primarily event-focused, however, suggesting that the methods may distort actual events. For this reason, conflict data were cross-validated at each company, using multiple sources. ${ }^{3}$ 


\section{Interaction Patterns}

\section{Social Network Comparisons across Firms: Statistical Analysis}

Uniplex ties among partners occur less often at Independent Accounting than among Playco executives. Across each type of uniplex tie, there are on average $30 \%$ fewer such ties among Independent partners than among Playco executives. For regular communication about work-related issues, $18 \%$ of the possible ties were constituted among Independent partners, while $50 \%$ of such ties exist at Playco. For informational interdependence, $11 \%$ of such ties exist among Independent partners, while $43 \%$ of these ties exist at Playco. Thirteen percent of the normative information ties among Independent partners exist, while $36 \%$ of such ties exist among Playco executives. Eleven percent of the ally ties at Independent exist, while $42 \%$ of such ties occur among Playco executives.

Differences in interaction patterns also appear when considering mean multiplex densities across the two firms. Just under $5 \%$ of ties with two dimensions exist between Independent partners, while $34 \%$ of such ties can be found among Playco executives. Three percent of the three-dimensional multiplex ties exist among Independent partners, while $29 \%$ of such ties exist among Playco executives. At Independent, $2 \%$ of the potential four-dimension ties exist among partners. At Playco, 27\% of such ties exist among executives.

These findings corroborate those from other large accounting firms and firms with matrix structures, respectively. Previous research on interpartner communication suggests that partners spend less than one-tenth of their time interacting with colleagues, spending far more time developing accounts with new clients or directing their own staffs (Wolf 1981; Montagna 1974). Previous research supports the relationship between matrix structures and high-density managerial social networks within departments, although communication across departments tends to be more sparse and formalized (Butler 1973; Davis 1987). The ethnographic data from each firm paint similar pictures as illustrated first by descriptions of an Independent partner's and then a Playco executive's typical day, excerpted from my field notes.

\section{Ethnographic Comparisons across Firms}

A Typical Day at Independent: Dolan of Tax. Dolan is an 18-year veteran of Independent: for the last 10 years he has been a partner. He is 44 years old. He arrives at the 50 -story black glass tower that houses the ten floors used by Independent by 6:00 a.m., greets me, and parks his Lincoln Towncar in an area of the parking garages reserved for Independent partners. A private elevator takes him to his 47 th floor office. Dolan barely acknowledges two partners arriving at approximately the same time. A large mahogany desk is at one end of Dolan's office with some chairs in front of it. Several piles of papers sit on a narrow table near the desk. An oblong meeting table with several chairs around it is at the opposite end of the office. Dolan has a personal computer and a terminal connected to the time-share system the entire practice uses. On Dolan's walls hang a college degree, a law degree, a CPA certification, and pictures of his wife and two children. One side of the office is completely windowed, affording a spectacular view of the city. I sit at the oblong table and make some notes about the office layout.

By 7:00 a.m. Dolan finishes reviewing notes he made into a mini tape recorder the previous day. The notes concern an upcoming bid to become the regular tax consultant of a natural gas supplier. He then calls the president of a client in the east (for whom he "saved" millions through an engagement with the client's subsidiary) and "personally" RSVP's to an invitation to the wedding of the president's youngest daughter. His administrative assistant, Laura, arrives at 7:00 a.m. Fifteen minutes later, Laura brings Dolan's morning mail, neatly organized into three stacks of ascending urgency, and a cup of coffee to him. She reminds him of a meeting with an engagement staff at 8:00 a.m., a client meeting at 10:00 a.m., another engagement meeting at 1 1:00 a.m., and a meeting with another client in Dolan's South County office at 3:00 p.m. He skims the stacks, finds a magazine, and thumbs through it while he sips his coffee. Ten minutes before eight, Dolan reviews some files for his engagement meeting. He opens his door at eight to find several associates carrying files and other materials. He reminds them that a "student" interested in the goings on of an accounting firm will be observing the meeting. One associate (a 
manager, the rank just below partner, who is second in command of the "staff') walks to the pc and inserts a floppy disk. The other associates are seated at the meeting table. The manager begins talking about data that have appeared on the computer's spreadsheet. The meeting lasts for one hour. Talk is confined mostly to question-and-answer format until Dolan raises two issues that he says "have not been dealt with systematically." The group focuses their attention on these questions and the spreadsheet is forgotten. The meeting ends at 9:15 with Dolan assigning various tasks to the staff. Dolan asks his manager to stay behind after the rest have departed and tells him to "keep his eye on Brown [another associate] . . . who didn't seem to know what was going on again."

After the manager has left, Dolan goes to another stack of files on the desk and begins reading them prior to his 10:00 meeting. He pauses and talks to me about the meeting. A discussion ensues about the backgrounds of the associates. Dolan asks that I step out for the meeting with the client due to the "confidential" nature of the anticipated discussion. The meeting ends a few minutes after ten and Dolan is met by a harried associate who must speak with him about a tax engagement that has taken some "unexpected turns." Dolan confers with the associate momentarily in the hall and then returns to his office to prepare for his 11:00 meeting. The meeting takes the same form as the 8:00 meeting and it ends by 12:00 p.m., whereupon Dolan and I go to lunch at the restaurant on top of Independent's building.

At lunch, a range of topics are covered, including my impressions of the associates, Dolan's oldest daughter, who is about to enter college, and Dolan's strategy for "selling" the client he is to meet in his South County office. Dolan jokingly apologizes for the lack of "action" I witnessed during the day, but observes that "that's what it's like around here [at Independent]." Lunch ends and Dolan and I return to the former's office to pick up some materials prior to driving to the South County office. The drive lasts for one and one-half hours, during which Dolan receives a phone call from Laura with a message from a prospective client. Arriving at the office at 2:45, Dolan greets his secretary, Janice, who says the client will be 30 minutes late. Dolan spends the extra time working on a draft of an engagement report for another South County client. The client arrives and I am allowed to stay. Dolan greets the client warmly and explains that a "young student" will be sitting in on the meeting. Dolan asks some questions about the client's firm and then talks about similar engagements he has performed in the same industry. The meeting ends at 4:00 with a promise by the client to "get back with Dolan by next week" with a decision on the engagement. Dolan and I drive back to the main office, where I parked my car. The day's observations end at 5:30 p.m.

In contrast to Independent Accounting, on any given day, Playco executives could be observed talking with each other in the hallways, elevators, and parking lots at their headquarters. Rapidly paced, informal meetings within departments tend to be a modal collective activity for Playco executives. More elaborate, ritualized product team meetings tend to dominate cross-departmental interaction. Additional evidence for these interaction patterns is provided by the following typical morning in the work activities of a vice president of research and development.

A Typical Day at Playco: Stennet of Research and Development. Stennet (44) is a ten-year veteran of the executive ranks at Playco, having held the title of senior vice president of research and development for five years. Stennet and I greet each other in the executive parking lot at Playco at 7:00 a.m. The lot surrounds a complex of single- and two-story buildings, in the middle of which rises the twenty-story "tower." Stennet closes the door on his Cadillac and hurries to the executive entrance of the tower. The executive entrance is separated from the main entrance to the tower and has private elevators. Stennet and I arrive at the 18th floor and are met by Jill, Stennet's secretary. She hands him several small pieces of yellow paper, each with some notes jotted on them. Stennet ushers me into his office, which is in a corner with floor-length windows on two sides of the room. Stennet sits at a large mahogany desk with his back against one wall. He has a round conference table across the room from his desk, as well as a small sink and private bathroom. Pictures of Stennet and others with large fish in their hands adorn the walls. A picture of his wife and three children sits on his desk.

He begins speaking to me in an excited manner: "See these [referring to the yellow pieces of paper]. Each one has to do with some meeting I have to go to or a message to call someone in R\&D. I've got a product team meeting to go to at nine this morning. Two guys there are going to duel it out on whether we should go total glitz on presenting our product line this year [at an industry-wide trade show] or not. Another one is a message from the president; another is a 
reminder from some personnel fool that I need to get him the evaluations of my vice presidents. I can trash that one; it'll take two weeks to talk to their product team leaders to get any data to put into a report." He continues to recount the rest of the yellow papers, noting that each one requires that he interact with another executive or middle manager. Stennet calls one of his vice presidents to ask him whether he is ready for his "duel" with his product team member. The two talk about how best to present their argument. Jill returns at 7:30 with Stennet's mail, which he does not look at and leaves in a stack on a side table near his desk. Ten minutes later, Brown, one of Stennet's vice presidents, enters his office to alert Stennet that the "princess of power" [the senior vice president of marketing] is going to be "gunning" for him at a meeting later in the week with the president of domestic affairs as a result of some "skirmishes" [arguments] between a vice president of $R \& D$ and a vice president of marketing. They decide to meet the next day to discuss strategy on how to "beat" the princess in the meeting.

Jones, a middle manager from engineering, has been waiting at Stennet's door while Stennet finishes with Brown. Before Jones can speak, Stennet tells Jones that if Bobson [Jones's superior in engineering] wants to talk with him he should come himself and that he doesn't speak to "errand boys." Jones leaves hurriedly. Stennet then asks Jill who he is to meet at 10:00 a.m. Jill launches into a description of three "hired gun artists" who want to "pitch" new product ideas. Stennet agrees to "keep the date" and asks that Jill ask Jordan, another vice president of R\&D, to attend the meeting and Sara, another of his secretaries, to take notes during the meeting. At $8: 10$, Stennet leaves the office to walk across the headquarters to the personnel department to attend a presentation by the senior vice president of personnel on restructuring executive retirement benefits at the firm. The presentation has three other executives in attendance and includes slides comparing the present with the new plan. Stennet leans over to one of his colleagues and whispers, "What a bunch of horseshit. They could have sent us a memo on this one.'

Back in the office by 9:15, Stennet is greeted by Jill, who tells him that Green [the princess of power] wants him to call her back and that Jordan may be too busy to attend the 10:00 a.m. meeting. Stennet sets his jaw and enters his office, asks me to make sure the door is wide open, and to listen to the "fireworks." Stennet calls Green, says hello, and begins listening. After a few minutes, he says, "Look, if you want to go to war on this one, fine. Fine, you do that. Look, don't get so hot. See you at the meeting, bye." Stennet explains that he and the princess are going to "duel" at the meeting regarding the primacy of marketing in setting "conceptual product delivery" deadlines for product teams. He then adds that she "gets too hot under the collar about these things." Stennet receives another phone call from a model maker in R\&D who is a "fishing buddy." Stennet and the caller talk for a few minutes and set a time to go fishing the next Sunday. Stennet then calls Jordan and says, "If you can't come, you can't come. Stop by this afternoon to look over some of their [the artists'] stuff. Hey, can you make it this Sunday to fish? OK, we'll talk this afternoon." The phone call ends.

At 9:50, Jill and Sara enter Stennet's office to announce the early arrival of the artists. Sara goes to Stennet's kitchen to make coffee and then seats herself slightly away from the round meeting table. At 10:00, Jill ushers the artists in to Stennet's office. After exchanging pleasantries, Stennet asks the artists what they "have" for him. They unfurl a large portfolio of product sketches. One of the artists talks for fifteen minutes about the sketches, after which Stennet asks him specific questions about how the artists believe the products fit in with existing product lines. The meeting lasts through lunch, which Stennet has ordered out through Sara. At 1:00 p.m., the meeting ends with Stennet assuring the artists that he will give serious consideration to their ideas. The artists seem pleased and leave all smiles.

One could continue to recount Stennet's day until its conclusion at 7:30 p.m. The portrait of interaction at Playco would be the same: Executives have greater interaction on task-related and affective dimensions than their Independent counterparts. There is also internal variation at each firm.

\section{Comparisons within Firms}

Network density comparisons across work units in each firm provide information about internal variation in executive interaction patterns.

Independent Accounting. Uniplex ties of any type occur infrequently among tax partners ( $13 \%$ of the uniplex ties possible), next highest among audit partners $(20 \%)$, and highest among management consulting partners $(41 \%)$. These differences may relate to the di- 
versity of management consulting engagements and the specialization of consulting partners who often blend their skills with colleagues to perform engagements. The contrasts in interaction patterns between management consulting and tax and audit are most striking when considering their multiplex relations. Tax partners do not report multiplex relations among themselves, while audit partners report $10 \%$ of the possible multiplex ties consisting of two dimensions only, regular communication and informational interdependence. Management consulting partners report $23 \%$ of their possible multiplex ties of two dimensions, $20 \%$ of their possible ties with three dimensions, and the existence of $11 \%$ of their four-dimensional ties. Finally, it should be noted that ties between partners in different practices are sparse. Densities in uniplex networks among partners of different practices range from $1 \%$ of the ally ties enacted to $5 \%$ of the regular communication ties enacted.

Playco. Internal variation among Playco top managers is most apparent when comparing interpersonal networks in departments and product teams. Fifty-two percent of the uniplex ties among departmental colleagues were activated, whereas product team members report $33 \%$ of their possible uniplex ties. This is especially apparent when one compares the densities for normative information sharing and conflict allies. Nearly $40 \%$ of the possible normative information ties are enacted in departments, while $17 \%$ of such ties are activated in product teams. Multiplex ties between Playco executives in departments and product teams display similar differences. Departmental colleagues have higher densities (than do product team members) of ties with two dimensions (45\% versus $23 \%$ ), three dimensions ( $26 \%$ versus $14 \%$ ), and four dimensions ( $18 \%$ versus $13 \%$ ). The sparsest ties exist among Playco executives who neither belong to the same product team nor work in the same department. For these executives, no more than $10 \%$ of the possible ties are activated, while multiplex tie densities range from $6 \%$ (for two dimensions) to less than $1 \%$ for multiplex ties of four dimensions.

In sum, the patterns of interaction at Playco and Independent display dramatic differences. At Independent we find sparse social ties and fragmented interaction patterns: partners largely keep to themselves, their engagement staffs, and their clients. The exception to this rule is the management consulting practice that has interaction patterns resembling the dense-knit networks in Playco departments. Variation exists at Playco as well: product teams, containing executives from different departments, have more fragmented interaction patterns than do departments. We examine now the patterns and beliefs about conflict management that occur in these two social settings.

\section{Patterns and Beliefs of Executive Grievance Expressions}

\section{Grievance Expressions at Independent Accounting}

Overall Patterns. The frequencies and percentages in Table 1 substantiate the claim that grievance pursuit in loose-knit networks will be subtle and nonconfrontational. Of the cases collected, $73 \%$ were handled covertly, while $27 \%$ were handled overtly.

Many of the covert grievances at Independent are expressed via combinations of toleration and temporary avoidance. Toleration entails inaction by a complainant pursuant to a grievance (e.g., Baumgartner 1984; Felstiner 1974; Merry 1979). Objectionable behavior that is tolerated includes "bad marketing decisions," alcoholism and drug use, personal style, how partners bill clients, or losing clients to rival firms. At Independent, most partners who suspend their grievances by tolerating offenders also resume "friendly" relations with them. Partners label this kind of behavior "learning to live" with colleagues' "eccentricities." In this sense, partners regard toleration as a way to smooth problems over until they wither away because the offender ceases to interact with the aggrieved, alters his or her behavior in a favorable manner, or the matter is simply forgotten by the aggrieved.

Temporary avoidance is another covert tactic used among Independent partners. Partners engage in avoidance by altering aspects of their work schedules, by not attending 
Table 1

Confrontational and nonconfrontational grievance expressions among partners at Independent Accounting.

\begin{tabular}{lcr}
\hline Behavior & Frequency & Percenta \\
\hline Covert expressions & & \\
Temporary avoidance & 24 & 31 \\
Toleration & 16 & 21 \\
Strategic alienation & 11 & 14 \\
Surveillance & $(3)^{\mathrm{a}}$ & - \\
Resignation & $(3)$ & 73 \\
& 57 & \\
Overt expressions & & 9 \\
Conciliatory negotiation & 7 & 6 \\
Counseling & 6 & - \\
Accusations & 5 & 27 \\
Replacement & $(2)$ & 100 \\
& 20 &
\end{tabular}

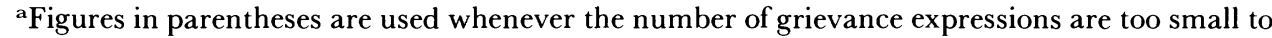
generate meaningful percentages. Percentages are provided to account for the total sample.

meetings with the offending parties, or by not communicating with offending parties when in their presence. For example, Holmes, a tax partner, began arriving at 5:00 a.m. and leaving by 9:00 a.m. in order to make "field visits" to clients before Ronelli, another tax partner whom he "despised," arrived to begin his work day. Rather than continue his early morning regime, Holmes arranged for an office on the opposite side of the building from Ronelli.

Partners also engage in a covert grievance expression they simply call "watching," "keeping tabs," or placing an offending party "under surveillance." Such surveillance occurs when an aggrieved party systematically gathers information about the activities of an opponent. Partners under surveillance rarely know such tactics are being employed against them. For example, Tucker, an audit partner, objected to his colleague Hall's request to use a staffer when Hall learned that he, Tucker, also wanted the same individual on his staff. Tucker acquiesced to Hall's insistence that the accountant was crucial for his engagement. In an interview, Tucker privately expressed his displeasure at "losing out on working with a hot prospect [to become partner]." Tucker admitted that he "kept tabs" on whether Hall "really groomed" the staffer "properly."

A covert grievance expression less prevalent than temporary avoidance, toleration, or surveillance occurs when partners seriously engage in some trivial activity as a response to a colleague's objectionable behavior. Partners refer to this as becoming "intentionally distracted" or "going into a routine." To some degree this tactic resembles what Goffman (1967:63) calls alienation from interaction, in which individuals "spontaneously become involved in unsociable solitary tasks" during interaction with others. Because of its purposive nature, this behavior could be called "strategic alienation." An example of strategic alienation occurred at a series of meetings in which Dales, a management consulting partner, nearly always began an intricate process of cleaning and lighting his pipe when Simpson, also in management consulting, spoke for any length of time. Dales reported in an interview that he "got so bored with [Simpson's] minutia [that ... he] wanted to let him know [he] was turned off and bored." Simpson never outwardly reacted to Dales's action. However, in a subsequent interview, Simpson noted Dales's "rude" behavior and 
admitted that he had begun to "not offer [his] opinions anymore at meetings" and "stopped talking as soon as [Dales] began cleaning his pipe."

Finally, resignation can be seen as an extreme form of avoidance. Only three instances of grievance-based resignations from the firm were collected during fieldwork. In two of the three instances recorded, resignation occurred after other forms of grievance expressions yielded little satisfaction to the aggrieved. Such was the situation when Ellis resigned in the aftermath of an accusation of double billing made by a client. Although he was exonerated of the charges in several meetings with the managing partner and the client, Ellis believed he had been wrongly accused by the client and that the managing partner and his colleagues had not supported his (Ellis's) "case" strongly enough. Faced with what he called "the hypocrisy of colleagueship," Ellis left Independent to join a rival firm.

The resolution (or lack thereof) of problems that are handled via toleration, avoidance, or surveillance, separately or together, takes several forms. In some cases, partners tolerate offending colleagues for years, as in the situation of a partner who served few clients and was believed by one partner "to be a drain on the firm." Mutual avoidance and surveillance can also last for years without any resolution by the parties in conflict. Avoidance and toleration thus resonate with what Bailey (1965:7) terms conflict "damping" in which the actors involved attempt to "symbolize" their own reasonableness by not being "quarrelsome." As Bailey argues, damping may not substantively affect the outcome of conflict in the sense of punctuating it with resolution. Instead, it merely reaffirms the proper etiquette of how to conduct arguments in a proper manner: in this setting, without direct confrontation.

In contrast to toleration, avoidance, or surveillance, strategic alienation and resignation operate symbolically and substantively. On the one hand, they symbolize the nonconfrontational stance that partners assume and understand as the proper way to handle conflict. On the other hand, they more directly affect conflict. Strategic alienation nonverbally communicates and dramatizes grievance expressions to offending parties and surrounding audiences and, in so doing, may have a substantive effect on the offending person's behavior. Resignation removes one of the principals from the context of grievances, thus ending it within the firm.

Relatively few grievance expressions involving hostile confrontation were observed or collected in the sample; all such cases were confined to quick verbal accusations, which usually were withdrawn and handled over the longer term using one of the modal covert tactics or via a restrained form of direct action. The same kinds of issues that draw covert tactics also draw overt tactics: the rating of nonpartner professionals, marketing policies, personal style, alcohol and drug use, parking space allocation, or decisions about the office's physical plant (e.g., whether the west-facing windows of partners' offices should be tinted darker).

The majority of confrontational situations involve some kind of conciliatory negotiation in which partners appear to be cordial, even apologetic, or, as they put it, "respectful." This was the situation in the aftermath of an argument between two management consulting partners, Grey and Williams, over whether to include executive personnel screening in their services. The two men met outside their offices and quietly resolved the issue, admitting that they had been "a bit out of control" when they previously argued with each other. It is interesting to note that negotiation also mixes the symbolic and substantive characteristics of conflict handling discussed above. In the example just given, Grey and Williams resolved their problem face-to-face, while also maintaining the customary Independent Accounting restraint in conflict handling.

"Counseling," as partners call it, takes a different form than conciliatory negotiation, and although it is symbolically consistent with the partnership's restrained conflict management, it is always intended to have a substantive effect on a problem. When practiced among partners, counseling entails one partner attempting to advise a colleague on how to alter his or her behavior toward some acceptable standard. As with therapeutic forms 
of social control in general (Horwitz 1982), the counselor generally focuses away from any particular "offense" and concentrates on a partner's overall behavior. Counseling can also lead to what partners refer to as "replacement": the removal of a partner from his or her duties and the replacement of that partner with another colleague. During fieldwork, replacement always resulted in the replaced partner leaving the firm, although partners claimed that sometimes replaced partners remained with the firm in reduced capacities.

It should also be noted that internal third parties acting to settle interpartner conflict is rare at Independent. Partners occasionally confide in one another, but instances of mediation or arbitration among partners did not occur during fieldwork.

Internal Variation. The customs of conflict management among Independent partners revolve around the nonconfrontation described above. Nonetheless, it is possible to discern internal variation within the partnership. Two responses to questions about how Independent partners "should" pursue grievances illustrate this variation.

Management consulting partner Vega: Of course one should try to minimize conflict with colleagues and be reasonable. But $\mathrm{I}$ also think that we in management consulting should try to resolve issues more openly; admit there are problems and work them out. I think that's true now in this practice. I was in tax for years, and people were quite afraid of open conflict. There's much more of a sense here [in management consulting] that you have to get things out in the open and confront the people involved, even if that means ruffling feathers.

Audit partner Josephs: Nobody likes conflict [by this, the informant meant hostile confrontation and covert grievances and tensions]. And nobody likes to talk about it. These are touchy issues. I believe that partners should do and do in fact do all they can to prevent conflict from happening, but it's sometimes inevitable. When it does happen, the professional thing to do is to handle it as quickly as possible without making waves; avoid the partner and get on with work.

Both partners echo wider sentiments at the partnership that favor nonconfrontation and maintaining a "reasonable" stance in interpartner conflict. Yet, Vega argues that confrontation is closer to the custom in the management consulting practice. Grievance expression patterns also vary across practices. All of the instances of conciliatory negotiation and accusations, for example, were collected in the denser social networks of the management consulting practice. Covert grievance expressions were collected in all practices. Differences in ways and beliefs of handling grievances, it should be noted, also provoke grievances. In several interviews, management consulting partners questioned the customs of conflict management in tax and audit. Tax and audit partners likewise criticized their consulting brethren, whom they felt sometimes spent too much time "talking things out." Confrontation, apparent in a minority of grievances at Independent, is the mode among Playco executives.

\section{Grievance Expressions at Playco}

Overall Patterns. A quick glance at Table 2 suggests that Playco executives have a much larger repertoire of grievance-handling tactics than partners at Independent Accounting. Nine distinct forms of grievance expressions were gathered among partners at Independent, whereas seventeen were gathered among executives at Playco. Of the interexecutive grievance expressions collected at Playco, $65 \%$ were handled overtly and $35 \%$ were handled covertly, supporting the hypothesis that executive grievances in dense-knit networks should routinely involve confrontation.

Playco colleagues are likely to approach those against whom they have a grievance and directly challenge their behavior, often insulting the target of their complaints in the process. Nearly one-third of the grievance expressions gathered involve open challenges and public insults. Nearly $50 \%$ (14 of 29 ) of these grievance expressions evolved into what Playco executives refer to as "shoot-outs" or "duels" at executive meetings. Duels have highly ritualized natures in which each adversary attempts to balance the scales with an opponent or upstage them. As one executive put it, "Your reputation, your honor is at 
Table 2

Confrontational and nonconfrontational grievance expressions among executives at Playco.

\begin{tabular}{lcc}
\hline Behavior & Frequency & Percentage \\
\hline Covert expressions & 9 & \\
Feigned ignorance & 8 & 9 \\
Secret complaining & 7 & 7 \\
Toleration & 4 & 7 \\
Temporary avoidance & $(3)$ & 4 \\
Covert retaliation & $(2)$ & - \\
Lumping & $(1)$ & - \\
Resignation & 36 & 35 \\
& & \\
Overt expressions & 17 & 17 \\
Challenge & 14 & 14 \\
Duel & 12 & 12 \\
Public insult & 7 & 7 \\
Negotiation & 6 & 6 \\
Feud & 5 & 5 \\
Arguments & $(2)$ & - \\
Fighting & $(2)$ & - \\
Mediation & $(1)$ & - \\
Resignation & $(1)$ & 65 \\
Firing & 67 & 100 \\
& 103 & \\
\multicolumn{1}{l}{ Totals } & & \\
\hline
\end{tabular}

stake in a duel. If you don't demonstrate you're equal or better than your opponent, you won't go far in this business [firm]."

A typical example of how challenges and insults evolve into duels occurred between Johnson, a sales vice president and Kolanski, the senior vice president of marketing. Johnson walked into Kolanski's office complaining that Kolanski had not supported his plan to expand a product line's geographical market after having agreed to do so. While addressing Kolanski, Johnson made sure the door was open so that, as he put it, "the world knew that I was challenging this bitch." He then challenged Kolanski to openly present an alternative to the plan they had agreed upon at the next product team meeting. According to the vice president, "I wanted to let her know that she couldn't get away with being a sunny day ally." The two executives then arranged a "duel" at a product team meeting at which they presented competing plans complete with "seconds" (their assistants). Kolanski, after several rounds of debate between the principals, finally withdrew her plan and admitted defeat.

In some instances, challenges and insults lead to collective feuds between principals and their supporters, as when Tover, a vice president, observed during a product team meeting that the "color scheme" in a remodeled wing of the headquarters tower looked like something out of a "bad nightmare." Unbeknownst to Tover, Bowden, his team colleague, had chosen the colors himself. Bowden in turn said that Tover's "taste was all in his mouth ... [and that] . . . he wouldn't know a creative color scheme if it bit him." An argument erupted between the two men, which in turn evolved into a challenge by Bowden for Tover to "come up with an alternative." Tover accepted the challenge and spent the next two weeks developing what he called "a multimedia presentation," which he unveiled in a product team meeting. Tover made his presentation, after which Bowden, who had been taking copious notes, rebutted several of Tover's arguments, point by 
point. This duel did not end with a definitive resolution, but continued for several months after fieldwork ended, including presentations to the office of the presidents and the board of directors. This conflict even came to have the moniker, "Colorgate" (evocative of the American "Watergate" political scandal of the early 1970s) in reference to its length and its increasing complexity. It also carried over into other product team meetings, as supporters of the two principals "dueled" each other on the issues, which had grown to symbolize the "image the firm wanted to present to visitors at its headquarters." Informal discussions and arguments at lunches and social occasions also occurred. In the meantime, the remodeling was halted. Furniture, equipment, and employees were simply moved back into the wing without it being finished.

Vengeful conflicts, such as those described above, are sometimes resolved by negotiations urged by the "civilizing" influences of each disputant's supporters or an executive who acts as a mediator. This is especially true in cases where the same alignment of supporters occurs for a long period of time (8-12 weeks). Barnes, a personnel vice president, has been known to "rescue" executives caught up in intractable conflicts via mediation. Barnes is also officially designated as the "executive development" officer and offers individual advice to executives about interpersonal conflict and other problems. In instances where Barnes acts as a mediator he often draws upon his reputation as a particularly "strong" executive and one who "tells it like it is" to influence the suspension of hostilities between executives.

Various atypical types of grievance expressions also dot the normative landscape at Playco. Among the more dramatic is physical fighting. Two instances in which Playco executives resorted to violence were recorded at Playco: one occurred in a product team meeting in which a duel evolved into a shoving match between the two principals; the other occurred in the parking lot as two executives carried over a previous conflict and resorted to fisticuffs as several thousand employees spectated. (Two employees near me actually bet five dollars between them on who would win the fight.) One grievance-based confrontational resignation by Beard, a vice president, was also recorded during fieldwork in the firm. Beard worked in finance and had experienced several "run-ins" with his superior over "departmental philosophy." After numerous negotiations, Beard told his superior he had had enough and gave a "two week notice" that he was leaving. In another situation, Olsen, a senior vice president of engineering, fired Pringle, a vice president in the department, after the former had lost a series of duels in product teams. Olsen believed Pringle to be incompetent and "a negative weight on the department's reputation in the firm."

Covert grievance expressions among Playco executives primarily occur through combinations of what they call "amnesia," "crying," "flying low," and "hiding." Although these grievance expressions can simply resolve a conflict, they also often preclude confrontation of the sort described above. "Amnesia" involves pretending to be oblivious to a colleague's behavior while at the same time tolerating it. "Flying low" involves acknowledging a grievance toward a colleague but at the same time doing nothing more about it. "Crying" is simply complaining secretly to another colleague. "Hiding" is understood by Playco executives to involve curtailing interaction with an aggrieved party.

Internal Variation. The patterns of grievance expressions and conflict management vary considerably among Playco executives along two dimensions: whether conflict occurs between executives who are considered "strong" or "weak" by their colleagues and whether it is between colleagues in the same department, on the same product team, or in neither the same department nor the same product team.

"Strong" and "weak" as labels applied to executives refer to the esteem with which they are held by their fellows. Those held in high esteem are often labeled as "strong" or "honorable," while those held in lesser esteem are labeled as "weak." Such labels at Playco largely derive from how executives conduct themselves interpersonally among 
their colleagues rather than from their success at developing profitable new products or contributing to the efficiency or effectiveness of the corporation. "Strong" interpersonal behavior at Playco consists of challenging colleagues who one finds offensive and answering challenges to one's behaviors in calculated and aggressive fashions. Playco executives talk a lot about the importance of "confronting" opponents and establishing a reputation that commands respect and underscores one's ability to play the "game." The game at Playco, as many of the examples alluded to above testify, consists of open conflict management in which one demonstrates the ability to publicly win in meeting duels or at least settle issues via negotiation. Just as Independent Accounting partners symbolically demonstrate their reasonableness and restraint by not confronting objectionable colleagues, Playco executives symbolically demonstrate their decisiveness, prowess, and competence by adherence to the rules of dealing with conflict through confrontation expressed in challenges, insults, and duels. Although substantive resolution is considered important and does result from these behaviors, most important in the minds of Playco executives is how one plays the game.

Executives labeled as "weak," in contrast, often engage in the constellations of covert grievance behaviors alluded to above or confront their opponents in less than predictable ways (e.g., all of the fights were between executives considered "weak" by their colleagues; meeting duels are less formalized and more chaotic among the "weak"). Moreover, weak executives engaged in the vast majority of covert grievance expressions (28 of $36,78 \%$ ). By not adhering to the rules of the game, "weak" executives symbolically demonstrate their cultural incompetence (from the perspective of "strong" executives), even though the substantive zero-sum outcomes from "weak" executives' unpredictable meeting duels are akin to what the more proper meeting duels of "strong" executives might yield.

In this way, conflict management at Playco resembles what occurs in many societies with well-defined codes of honor (see, for example, Bourdieu 1965; Rieder 1984; WyattBrown 1984; Black 1990:44-47). Codes of honor typically organize confrontation as a balancing of the scales between opponents, in one sense a negative "norm of reciprocity" (e.g., Gouldner 1960). At Playco, the meeting duel is the preferred way to pursue grievances, although other patterns commingle with this process. In social settings that contain well-developed codes of honor it is most important that combatants give good accounts of themselves whether they win or lose. And this notion is certainly paramount at Playco. As one top manager noted, the "strong" or "honorable" Playco executive "wins with dignity and loses with dignity." In this sense, the normative structure at Playco differs dramatically from that at Independent Accounting. Whereas negative reciprocity dominates the normative landscape at Playco, inaction or restraint characterizes Independent partners' beliefs about appropriate ways to manage conflict.

Although a normative system akin to a code of honor provides the "rules of the game" for managing conflict at Playco, the social distance between adversaries patterns the way in which the rules of the game are played out in particular situations. Five of the seven instances of negotiation, for example, occurred in the dense-knit social networks of departmental colleagues. All but one of the meeting duels occurred between product team members who have weaker social ties to each other. Executives who work neither in the same department nor the same product team are the most likely candidates to engage in collective feuds ( 5 out of 6 feuds recorded during fieldwork were between executives with the weakest social ties with each other). At the same time, all of the avoidance during fieldwork occurred among Playco executives who did not have work-unit ties with each other and who were considered by their "stronger" colleagues to be "weak" as well. Among those "weak" executives who practice avoidance, all considered avoidance behaviors to be the only way to "wound" an opponent.

\section{Organizational Seriousness and Executive Grievances}

At Independent, conflicts perceived as serious by disputants focus on significant company financial investments and losses, unethical behavior, mobility from middle man- 
agement to executive positions, long-range planning, and executive compensation. Playco executives believe many of the same issues to be serious, with the addition of foreign political developments and the opening of new overseas markets related to the firm's overseas operations. According to Table 3, the seriousness of issues slightly affects the likelihood of overt grievance expressions at both firms.

At Playco, $66 \%$ of the conflicts considered serious by the participants were handled directly, using their particular combination of challenges, duels, and negotiations. Slightly fewer of the issues defined as less serious by Playco executives $(62 \%)$ were handled via their typical overt methods. This same tendency appears in the Independent data, where $34 \%$ of the serious conflicts were handled via their versions of confrontation-conciliatory negotiation, counseling, accusations, and replacement-while $21 \%$ of the less serious conflicts were handled confrontationally. Still, the overall ratio of covert and overt grievance expressions remains roughly the same at both firms for both serious and less serious issues (compare All Issues in Table 3).

A few Independent partners expressed the belief that more serious conflicts should be handled "directly" so as to minimize the "damage" to the partnership. Yet, they also qualified these statements with arguments about "appropriate" ways to handle conflict. As one partner noted:

There are other issues to be considered that don't just involve what is the most efficient way to do things; like treating your colleagues with respect and not interfering with their affairs. A lot of issues that seem important should be handled with a sit-down between the partners involved, but no one wants to get involved in a messy conflict with someone. It's really not the way we do things around here.

At Playco, executives spoke often of factors unrelated to organizational seriousness. One vice president argued strongly about "not letting people get away with anything" because it could impugn an executive's reputation and leave him without executive allies. As another executive put it, "an executive without honor or allies is dead in this company."

\section{Discussion and Conclusion}

At the outset of this work, it was hypothesized following a choice approach to conflict management that grievances defined by executive disputants as serious and in need of immediate attention would be managed confrontationally and that grievances defined as

Table 3

Grievance expressions among executives according to perceived seriousness of conflict issues and corporate setting.

\begin{tabular}{|c|c|c|c|c|c|c|}
\hline \multirow[b]{3}{*}{ Grievance expression } & \multicolumn{6}{|c|}{ Perceived seriousness of conflict issues and corporate setting } \\
\hline & \multicolumn{2}{|c|}{ Serious issues $^{\mathbf{a}}$} & \multicolumn{2}{|c|}{ Minor issues } & \multicolumn{2}{|c|}{ All issues } \\
\hline & $\mathrm{IA}^{\mathrm{b}}$ & Playco & IA & Playco & IA & Playco \\
\hline Nonconfrontation & $\begin{array}{r}66 \\
(26)\end{array}$ & $\begin{array}{r}28 \\
(15)\end{array}$ & $\begin{array}{r}79 \\
(31)\end{array}$ & $\begin{array}{r}38 \\
(21)\end{array}$ & $\begin{array}{r}73 \\
(57)\end{array}$ & $\begin{array}{r}35 \\
(36)\end{array}$ \\
\hline Confrontation & $\begin{array}{r}34 \\
(13)\end{array}$ & $\begin{array}{r}72 \\
(44)\end{array}$ & $\begin{array}{l}21 \\
(7)\end{array}$ & $\begin{array}{r}62 \\
(23)\end{array}$ & $\begin{array}{r}27 \\
(20)\end{array}$ & $\begin{array}{r}65 \\
(67)\end{array}$ \\
\hline Total percent & 100 & 100 & 100 & 100 & 100 & 100 \\
\hline $\begin{array}{c}\text { Total grievance } \\
\text { expressions }\end{array}$ & (39) & (59) & (38) & (44) & (77) & (103) \\
\hline
\end{tabular}

${ }^{a}$ By percent. Figures in parentheses indicate case frequencies.

${ }^{\mathrm{b}} \mathrm{IA}=$ Independent Accounting.

Note: For serious issues, $\chi^{2}=16.46, \mathrm{df}=1, p<.001$; for minor issues, $\chi^{2}=10.06, \mathrm{df}=1$, $p<.01$; for all issues, $\chi^{2}=26.95, \mathrm{df}=1, p<.001$. 
less serious by aggrieved executives would be managed without confrontation. The results herein lend little support to these hypotheses. A choice approach would not predict partner nonconfrontation at Independent as a way to handle grievance issues defined as serious; nor would confrontation occur over many of the issues perceived as less serious by Playco executives.

The present findings lend more support to the second set of hypotheses about conflict management, that corporate executives in loose-knit intra-organizational networks should manage conflict nonconfrontationally while executives in dense-knit networks should routinely confront each other with grievances. To be a partner at Independent Accounting means having a great deal of autonomy in one's actions, being socially distant from one's colleagues, and symbolizing one's professional station in the firm by handling conflict with little fanfare. To be an executive at Playco means having a great deal of interaction with departmental colleagues, being able to call on them as supporters in conflicts (typically with interdepartmental adversaries), and symbolizing one's honor as an executive by winning arguments against adversaries in meeting duels. Although these two visions are the overarching customs of conflict management in each firm, pockets of differentiation exist in the firms associated with different kinds of social networks. At Independent Accounting, management consulting partners subscribe to the overall minimalist culture of the organization, but experience denser social networks than their colleagues in tax or audit and are more likely to confront opponents. Aggrieved executives at Playco who have the greatest social distance from each other are also those most likely to engage in avoidance. The results suggest three general implications about (1) the occasional disjunction observed between executive beliefs and conflict management behaviors, (2) executive decision making, and (3) the isomorphism between social context and conflict management.

Some executives in both firms espoused beliefs about conflict management consistent with the choice perspective, while the majority of executives talked about precepts and accounts of conflict management that emphasized concerns other than organizational health and efficiency. It is interesting to note the type of executive prone to espousing the "choice" perspective of conflict management: the youngest and those who had been educated at elite business schools and universities. Perhaps it is those executives closest to the received wisdom of our business schools and universities, in which choice theory dominates (March 1988), who feel compelled to espouse the received wisdom. Those farther away from these institutions (in terms of experience) may be more prone to make sense of their actions within their local social contexts. This evidence implies that a wide crevasse exists between the realities of managerial decision making and formal education about decision making.

Yet, the crevasse is beginning to close as more scholars take serious notice that "choice" is a convenient yet inaccurate way to characterize managerial decision making. Fligstein (1990:4), for example, argues that managerial courses of action arise not out of absolute maxims of efficiency but out of "the social context in which managers operate." Most salient about such contexts are norms and social structures that constrain and enable particular managerial actions. Similarly, Dimaggio and Powell (1991) write that managerial action contains greater degrees of normative behavior than most choice-oriented theories are willing to admit. In these senses, then, managerial action is oriented toward "rule-following, as the matching of rules, procedures and routines to appropriate situations" (March and Sevon 1988:434, emphasis in original).

But where do such rules, procedures, and routines originate? Some are institutionalized in formal organizational practices, some are derived from law and other state practices, and some derive from prevailing economic and social ideologies (Fligstein 1990). The foregoing analysis suggests that another important source of such rules is the structure of interpersonal relations. Thus, it may be wise for researchers of large economic organizations to focus more attention on how interpersonal networks mediate between 
individual managers and wider cultural and social structural arrangements (e.g., Granovetter 1985).

A final implication of the present work concerns the unusually good "fit" between the normative bases of routine nongrievance behavior and the normative bases of routine conflict management. Black (1990:61) argues that routine conflict management is "isomorphic" with the social setting in which it occurs. Routine conflict management is not aberrant behavior, but "reproduces" its social context. Thus, where people experience atomization and social distance, as among Independent Accounting partners, they will also experience avoidance in their grievance pursuits. Where people confront one another over nongrievance-related matters, as at Playco, they will interact in similar modes to pursue their grievances.

To strengthen this general claim, consider the relationship between social context and conflict management in a business environment far removed from the setting of the present study: Japanese white-collar bureaucracies. Rohlen (1974:111) reports that modal grievance expressions in Japanese bureaucracies "rarely take the form of open confrontation with authority or refusal to perform required work. . . . Disagreement and criticism as well as unhappiness, can be expressed through acts of subtle nonconformity." Rohlen also reports that Japanese white-collar workers display high social solidarity among themselves and devotion to their organizations. These findings would seem to undermine the claims advanced in this article until one closely examines the nature of social ties in the Japanese workplace. Rohlen (1974:119) notes that interaction among white-collar members of Japanese firms is "characterized by . . . little capacity to separate the people from their roles." To be a Japanese white-collar worker is to have all one's interpersonal relations mediated by the organization; strong ties to colleagues mean strong ties to the organization. It may thus be difficult to mobilize allies in interpersonal conflict. To do so would be to act against the interests of the organization, and in one sense, to act against one's self (because individuals are caught in nonpermeable social roles as organizational members). Consistent with the arguments of this article, where people are atomized without allies, they will be more likely to defer to rather than to confront adversaries. The interpersonal nonconfrontation evident in Japanese firms may therefore reproduce the atomization and deference Japanese white-collar workers routinely experience in their daily roles as members of large organizations.

The situation is quite different in American firms. There, the individual interests of white-collar workers often diverge from those of the organization, and organizational roles are more permeable, with individuals being socially connected to others in a variety of different ways (Coleman 1982; Hirsch 1987). It is not surprising, therefore, to find such social diversity reflected in the diversity of conflict management across American whitecollar settings.

Studying up in large Anglo-American corporations may prove enlightening in unanticipated ways. Rather than finding powerful, exotic people capable of parceling out social context and following their visions of an efficient "big picture," we may instead find pragmatic individuals acting within the normative contours of their social contexts, much as people of less privileged social positions do.

\section{Notes}

Acknowledgments. Parts of this paper were presented at the Sunbelt Social Networks Meetings, San Diego, 1988, and at the annual meetings of the American Sociological Association, Atlanta, 1988. Support for this work was provided by a Junior Fellowship at Harvard Law School and the Program in Law and Social Sciences of the National Science Foundation (Grant SES-8508349). Donald Black, Donald Cressey, Keith M. Morrill, Ruth D. Morrill, Laura Nader, Alesandro Pizzorno, Harrison C. White, and personnel at "Independent Accounting" and "Playco" provided invaluable comments and support during fieldwork. M. P. Baumgartner, Donald Black, Michael Burgoon, Roberto M. Fernandez, Kathleen J. Ferraro, Neil Fligstein, Charles Kadushin, Roger V. Gould, Harrison C. White, and anonymous reviewers provided helpful methodological leads and comments on earlier drafts. 
${ }^{1}$ More ethnographic detail on the setting and individual conflict management behaviors for both companies can be found for Independent Accounting in Morrill (1992) and for Playco in Morrill (1991).

2Two partners at Independent Accounting were unable to be interviewed because one was on extended sick leave and the other was on extended leave to another large, out-of-state regional office. The four executives excluded from the Playco network analysis are from personnel $(n=2)$ and finance $(n=2)$. None of these executives are assigned to product teams or have regular interaction with other executives except one of the personnel vice presidents, who occasionally intervenes between conflicting executives as a mediator. His actions are discussed below. Playco also has ten executives who work in its foreign offices and were not available for systematic interviewing. Fragmented evidence on their disputing suggests it has a much more nonconfrontational nature.

${ }^{3}$ Informant confidentiality was protected using a variety of strategies. I was able to secure agreement from all informants that they would not ask any questions of the researcher about specific cases and individuals. I cross-checked data by asking general questions about departments and work groups, and informants produced stories about the cases I had collected from other sources. Occasionally, information about the same cases would vary considerably across sources. Some of this variation could be attributed to different vantage points of informants and was built into the complexity of the cases as they were written into ethnographic text. At other points, such discrepancies resulted from fabrication and memory lapse.

\section{References Cited}

Abbot, A.

1988 The Systems of Professions. Chicago: University of Chicago Press.

Bailey, F. G.

1965 Decisions by Consensus in Councils and Committees: With Special Reference to Village and Local Government in India. In Political Systems and the Distribution of Power. M. Banton, ed. Pp. 1-20. London: Tavistock.

Barnes, J. A.

1969 Networks and Political Processes. In Social Networks in Urban Situations. J. C. Mitchell, ed. Pp. 51-76. Manchester: Manchester University Press.

Baumgartner, M. P.

1984 Social Control in Suburbia. In Toward a General Theory of Social Control, Volume 2: Selected Problems. D. Black, ed. Pp. 79-103. Orlando, FL: Academic Press.

1988 The Moral Order of a Suburb. New York: Oxford University Press.

Bergmann, T. J., and R. J. Volkema

1989 Understanding and Managing Interpersonal Conflict at Work: Its Issues, Interactive Processes, and Consequences. In Managing Conflict: An Interdisciplinary Approach. M. A. Rahim, ed. Pp. 7-19. New York: Praeger.

Black, D.

1976 The Behavior of Law. New York: Academic Press.

1984 Social Control as a Dependent Variable. In Toward a General Theory of Social Control, Volume 1: Fundamentals. Pp. 1-36. Orlando, FL: Academic Press.

1990 The Elementary Forms of Conflict Management. In New Directions in the Study of Justice, Law, and Social Control (School of Justice Studies, Arizona State University). Pp. 4369. New York: Plenum Press.

Bohannan, P.

1967 Law and Warfare: Studies in the Anthropology of Conflict. Austin: University of Texas Press.

Bourdieu, P.

1965 The Sentiment of Honour in Kabyle Society. In Honour and Shame: The Values of a Mediterranean Society. J. G. Peristiany, ed. Pp. 191-244. Chicago: University of Chicago Press.

Buckle, L. G., and S. R. Thomas-Buckle

1983 Doing Unto Others: Dispute Processing in an Urban American Neighborhood. In Neighborhood Justice: Assessment of an Emerging Idea. R. Tomasic and M. M. Feeley, eds. Pp. 78-90. New York: Longman.

Butler, A. E.

1973 Project Management: A Study in Organizational Conflict. Academy of Management Review 16:84-101. 
Cain, M., and K. Kulcsar

1981-82 Thinking Disputes: An Essay on the Origins of the Dispute Industry. Law and Society Review 16:375-402.

Coleman, J. S. 1982 The Asymmetric Society. Syracuse, NY: Syracuse University Press.

Collins, O. F., and D. G. Moore 1970 The Organization Makers. New York: Appleton.

Colson, E. 1953 Social Control and Vengeance in Plateau Tonga Society. Africa 23:199-212.

Davis, S. M. 1987 Future Perfect. Reading, MA: Addison-Wesley.

Davis, S. M., and P. R. Lawrence 1977 Matrix. Reading, MA: Addison-Wesley.

Dimaggio, P. J., and W. W. Powell 1991 Introduction. In The New Institutionalism in Organizational Analysis. P. J. Dimaggio and W. W. Powell, eds. Chicago: University of Chicago Press. (In press.)

Felstiner, W. L. F.

1974 Influences of Social Organization on Dispute Processing. Law and Society Review 9:6394.

Fligstein, $\mathrm{N}$.

1990 The Transformation of Corporate Control. Cambridge, MA: Harvard University Press.

Freeman, L. C., A. K. Romney, and S. G. Freeman 1987 Cognitive Structure and Informant Accuracy. American Anthropologist 89:310-325.

Frost, P. J.

1987 Power, Politics, and Influence. In Handbook of Organizational Communication: An Interdisciplinary Perspective. F. M. Jablin, L. L. Putnam, K. H. Roberts, and L. W. Porter, eds. Pp. 503-548. Newbury Park, GA: Sage.

Geertz, C.

1973 The Interpretation of Cultures. New York: Basic Books.

Gluckman, M. 1973[1956] Custom and Conflict in Africa. New York: Harper and Row.

Goffman, E. 1967 Interaction Ritual. Garden Gity, NY: Doubleday.

Gouldner, A. W.

1960 The Norm of Reciprocity: A Preliminary Statement. American Sociological Review 25:161-178.

Granovetter, $\mathrm{M}$.

1985 Economic Action and Social Structure: The Problem of Embeddedness. American Journal of Sociology 91:481-510.

Greenhouse, G. J.

1986 Praying for Justice: Faith, Order, and Community in an American Town. Ithaca, NY: Cornell University Press.

Gulliver, P. H.

1979 Disputes and Negotiations: A Cross-Cultural Perspective. New York: Academic Press.

Hirsch, P.

1987 Pack Your Own Parachute: How to Survive Mergers, Takeovers, and Other Corporate Disasters. Reading, MA: Addison-Wesley.

Horwitz, Allan V.

1982 The Social Control of Mental Illness. New York: Academic Press.

1990 The Logic of Social Control. New York: Plenum Press.

Kanter, R. M.

1977 Men and Women of the Corporation. New York: Basic Books.

Killworth, P. D., and H. R. Bernard 1976 Informant Accuracy in Social Network Data. Human Organization 3:269-286.

Koch, K.

1974 War and Peace in Jalemo: The Management of Conflict in Highland New Guinea. Cambridge, MA: Harvard University Press. 
Kolb, D. M., and J. M. Bartunek, eds.

1992 Disputing Behind the Scenes: New Perspectives on Conflict in Organizations. Newbury Park, GA: Sage.

Kotter, J. P.

1982 The General Managers. Cambridge, MA: Harvard University Press.

Lauman, E. O., P. V. Marsden, and D. Prensky

1982 The Boundary Specification Problem in Network Analysis. In Applied Network Analysis:

Structural Methodology for Empirical Social Research. R. S. Burt and M. J. Minor, eds. Pp.

18-34. Beverly Hills, CA: Sage.

Llewellyn, K., and E. A. Hoebel

1983[1941] The Cheyenne Way: Conflict and Case Law in Primitive Jurisprudence. Norman:

University of Oklahoma Press.

Macaulay, S.

1963 Non-contractual Relations in Business: A Preliminary Study. American Sociological Review 28:55-67.

Maister, D.

1984 Partnership Politics. American Lawyer (October):6-9.

March, J. G.

1988 Introduction: A Chronicle of Speculations about Organizational Decision-Making. In Decisions and Organizations. Pp. 1-21. Oxford: Basil Blackwell.

March, J. G., and G. Sevon

1988 Gossip, Information and Decision-Making. In Decisions and Organizations. J. G. March, ed. Pp. 429-442. Oxford: Basil Blackwell.

Menkel-Meadow, G. J.

1983 The Transformation of Disputes by Lawyers: What the Dispute Paradigm Does and Does

Not Tell Us. Paper presented at the Law and Society Association, Denver.

Merry, S. E.

1979 Going to Court: Strategies of Dispute Settlement in an American Urban Neighborhood. Law and Society Review 13:891-925.

1990 Getting Justice and Getting Even: Legal Consciousness among Working-Class Americans. Chicago: University of Chicago Press.

Merry, S. E., and S. Silbey

1984 What Do Plaintiffs Want? Reexamining the Concept of Dispute. Justice System Journal 9:151-178.

Minor, M. J.

1983 New Directions in Multiplexity Analysis. In Applied Network Analysis: A Methodological Introduction. R. S. Burt and M. J. Minor, eds. Pp. 223-244. Beverly Hills, CA: Sage.

Mintzberg, $\mathrm{H}$.

1973 The Nature of Managerial Work. New York: Harper and Row.

Mitchell, J. C.

1969 The Concept and Use of Social Networks. In Social Networks in Urban Networks. Pp. 1-

50. Manchester, England: Manchester University Press.

Montagna, P. D.

1974 Certified Public Accounting: A Sociological View of a Profession in Change. New York: Scholars Book.

Morrill, C.

1989 The Management of Managers: Disputing in an Executive Hierarchy. Sociological Forum 4:387-409.

1991 Conflict, Management Honor, and Organizational Change. American Journal of Sociology 97. (In press.)

1992 The Private Ordering of Professional Relations. In Hidden Conflict in Organizations: Uncovering Behind-the-Scenes Disputes. D. M. Kolb and J. M. Bartunek, eds. Newbury Park, CA: Sage. (In press.)

Nader, $L$.

1969 Up the Anthropologist: Perspectives Gained from Studying Up. In Reinventing Anthropology. D. Hymes, ed. Pp. 284-311. New York: Random House.

Nader, L., and H. F. Todd, Jr., eds.

1978 The Disputing Process: Law in Ten Societies. New York: Columbia University Press. 
Rieder, J.

1984 The Social Organization of Vengeance. In Toward a General Theory of Social Control, Volume 1: Fundamentals. D. Black, ed. Pp. 131-162. Orlando, FL: Academic Press.

Rohlen, T. P.

1974 For Harmony and Strength: Japanese White-Collar Organization in Anthropological Perspective. Berkeley: University of California Press.

Starr, J.

1978 Turkish Village Disputing Behavior. In The Disputing Process: Law in Ten Societies. L. Nader and H. F. Todd, Jr., eds. Pp. 122-151. New York: Columbia University Press.

Van Maanen, J., and S. R. Barley

1985 Cultural Organization: Fragments of a Theory. In Organizational Culture. P. J. Frost, L. F. Moore, M. R. Louis, C. C. Lundberg, and J. Martin, eds. Beverly Hills, CA: Sage.

Van Velsen, J.

1967 The Extended-Case Method and Situational Analysis. In The Craft of Social Anthropology. A. L. Epstein, ed. Pp. 129-149. London: Tavistock.

Walton, R. E.

1969 Interpersonal Peacemaking: Confrontations and Third Party Consultation. Reading, MA: Addison-Wesley.

Wolf, F. M.

1981 The Nature of Managerial Work: An Investigation of the Work of the Audit Manager. Accounting Review 16:861-881.

Wyatt-Brown, B.

1984 Southern Honor: Ethics and Behavior in the Old South. New York: Oxford University Press. 